\title{
An end-channel amperometric detector for microchip capillary electrophoresis
}

\author{
Youyi $\mathrm{Wu}^{\mathrm{a}}$, Jin-Ming Lin ${ }^{\mathrm{a}, *}$, Rongguo $\mathrm{Su}^{\mathrm{a}}$, Feng $\mathrm{Qu}^{\mathrm{a}}$, Zongwei Cai ${ }^{\mathrm{b}}$ \\ ${ }^{a}$ Research Center for Eco-Environmental Sciences, Chinese Academy of Sciences, P.O. Box 2871, Beijing 100085, PR China \\ ${ }^{\mathrm{b}}$ Department of Chemistry, Hong Kong Baptist University, Kowloon Tong, Hong Kong, China
}

Received 14 January 2004; received in revised form 15 February 2004; accepted 17 February 2004

Available online 19 May 2004

\begin{abstract}
An end-channel amperometric detector with a guide tube for working electrode was designed and integrated on a home-made glass microchip. The guide tube was directly patterned and fabricated at the end of the detection reservoir, which made the fixation and alignment of working electrode relatively easy. The fabrication was carried out in a two-step etching process. A $30 \mu \mathrm{m}$ carbon fiber microdisk electrode and Pt cathode were also integrated onto the amperometric detector. The characteristics and primary performance of the home-made microchip capillary electrophoresis (MCCE) were investigated with neurotransmitters. The baseline separation of dopamine (DA), catechol (CA) and epinephrine (EP) was achieved within $80 \mathrm{~s}$. Separation parameters such as injection time, buffer components, pH of the buffer were studied. Relative standard deviations of not more than $6.0 \%$ were obtained for both peak currents and migration times. Under the selected separation conditions, the response for DA was linear from 5 to $200 \mu \mathrm{M}$ and from 20 to $800 \mu \mathrm{M}$ for CA. The limits of detection of DA and CA were 0.51 and $2.9 \mu \mathrm{M}$, respectively $(\mathrm{S} / \mathrm{N}=3)$.
\end{abstract}

(C) 2004 Elsevier B.V. All rights reserved.

Keywords: Microchip capillary electrophoresis; End-channel amperometric detection; Guide tube; Two-step etching; Carbon fiber microdisk electrode

\section{Introduction}

Microchip capillary electrophoresis (MCCE) has been an interesting and booming research topic since Manz and co-workers $[1,2]$ demonstrated the feasibility of chemical analysis system on a glass substrate using an electrokinetic phenomenon. It has primary benefits of micro total analysis system ( $\mu$-TAS) and capillary electrophoresis (CE), such as fast separation, high efficiency, low consumption of reagents and portability, etc. [3]. However, sensitive and miniature detection method was essential to fully exhibit the advantages of MCCE. Although laser-induced fluorescence (LIF) was the most widely used detection method for its highly sensitivity [4], conventional LIF device was rather complicated and expensive which made the miniaturization difficult. Diode laser was small but only available in a limited number of wavelengths [5]. Furthermore, derivatization the analyte with fluorophore was often necessary. MCCE with

\footnotetext{
* Corresponding author. Tel.: +86-10-62841953; fax: +86-10-62841953.

E-mail address: jmlin@mail.rcees.ac.cn (J.-M. Lin).
}

mass spectrometry (MS) provided much chemical information of analyte but not ideal for drawbacks such as inherently unportable, costly and less sensitive [6]. Chemiluminescence (CL) was a sensitive detection method especially to some metal ions $[7,8]$, which components are also simple, but accessorial devices (e.g. pump) were needed to mix all kinds of reagents and its susceptivity to $\mathrm{pH}$ as well as flow rate also weakened the merits.

Electrochemical detection would be a good alternative for its inherent miniaturization and high sensitivity. Among that, amperometric detection is the most sensitive and widely used in MCCE. More than 60 relative papers and several reviews [3,9] had been published, which were classified into off-channel, in-channel and end-channel detection based on the location of working electrode in respect to the separation channel. Because of the trivial effect of separation field on the detection circuit and its simplification, end-channel amperometric detection was the predominated detection mode (about $80-90 \%$ articles employed this method). Mathies and co-workers [10] reported the first end-channel detection MCCE in 1998. Martin et al. [11] firstly adopted two working electrodes in end-channel electrochemical detection. In 
end-channel detection, though the accurate alignment between working electrode and separation channel was difficult, a few relative works had been reported. Lunte and co-workers $[12,13]$ fabricated separation and injection channel in one PDMS layer, with electrode channel in another one. After the working electrode was placed and fixed in electrode channel, separation channel was vertically aligned with working electrode under a light microscope, at the same time, two PDMS layers were reversibly bonded. García and Henry [14] adopted analogous alignment method except two PDMS layers were irreversibly bonded. Wang et al. [15-18] performed the alignment by a plastic screw and the distance between working electrode and separation channel was about $50 \mu \mathrm{m}$. Zeng et al. [19] firstly designed and fabricated a home-made guide tube in order to precisely alignment and quickly replacement the working electrode, the result was fairly good but the fabrication process of the guide tube, the working electrode as well as the detector was rather laborious and complicated.

In this work, we reported an end-channel amperometric detector where a guide tube for alignment of working electrode was formed when two glass slides bonded. Mask pattern with guide tube and a two-step etching process were needed, which was not complex. The size of the guide tube can be controlled by adjusting the etching time which meant the alignment between working electrode and separation channel could be achieved precisely. The primary performance of the detector was also investigated.

\section{Experimental}

\subsection{Reagents}

All reagents were of analytical grade. 2-( $N$-morpholino $)$ ethanesulfonic acid (MES) and epinephrine (EP) hydrochloride were purchased from Sigma (St. Louis, USA). Dopamine (DA) hydrochloride was obtained from Fluka
(USA) and Catechol (CA) was from Ankara Chemicals (Japan). A $10 \mathrm{mM}$ DA stock solution containing $0.1 \mathrm{M}$ $\mathrm{HClO}_{4}$ was prepared and diluted to desired concentration with pure water. The $20 \mathrm{mM} \mathrm{CA}$ and EP stock solutions were respectively prepared in $0.1 \mathrm{M} \mathrm{HClO}_{4}$ and were diluted to specific concentration with pure water. A $20 \mathrm{mM}$ MES buffer was prepared by dissolving proper amount MES in pure water and adjusted to $\mathrm{pH} 6.4$ with $0.1 \mathrm{M} \mathrm{NaOH}$. The stock solutions were placed in a refrigerator and prepared again every 3 weeks. A $10 \mathrm{mM}$ phosphate buffer was prepared as the running buffer and the acidity was adjusted with $0.1 \mathrm{M}$ $\mathrm{HCl}$ or $0.1 \mathrm{M} \mathrm{NaOH}$ when it was necessary. All solutions were filtered with $0.45 \mu \mathrm{m}$ cellulose acetate film (Shanghai Xinya Purifying Equipments Co., China) before use.

Pure water (18.3 M $\Omega \mathrm{cm}$ resistivity) was made by passing deioned water through Barnstead Easypure LF compact pure water system (Dubuque, USA).

\subsection{Apparatus}

High voltage up to $30 \mathrm{kV}$ was provided with a $\mathrm{HV}$ source (Shanghai Institute of Nucleus, CAS, China). Electrochemical detection was performed on a CHI 800 electrochemical analyzer (Shanghai Chenhua Instrument Co., China). To minimize the interference of external electric field, a home-made Faraday cage was used to house the whole analysis system. A microscope with CCD camera (Moticam 1300, China), which was connected to a computer and controlled by Motic software (China), was employed to measure the channels.

\subsection{Chip microfabrication}

A $6.3 \mathrm{~cm}$-long square glass (Shaoguang Microelectric, China) with predeposit $145 \mathrm{~nm}$ thick $\mathrm{Cr}$ layer and $570 \mathrm{~nm}$ thick AZ photoresist was exposed beneath the designed mask (Fig. 1a) under an UV lamp, then developed and etched. Separation and injection channels were etched in $0.25 \mathrm{M}$

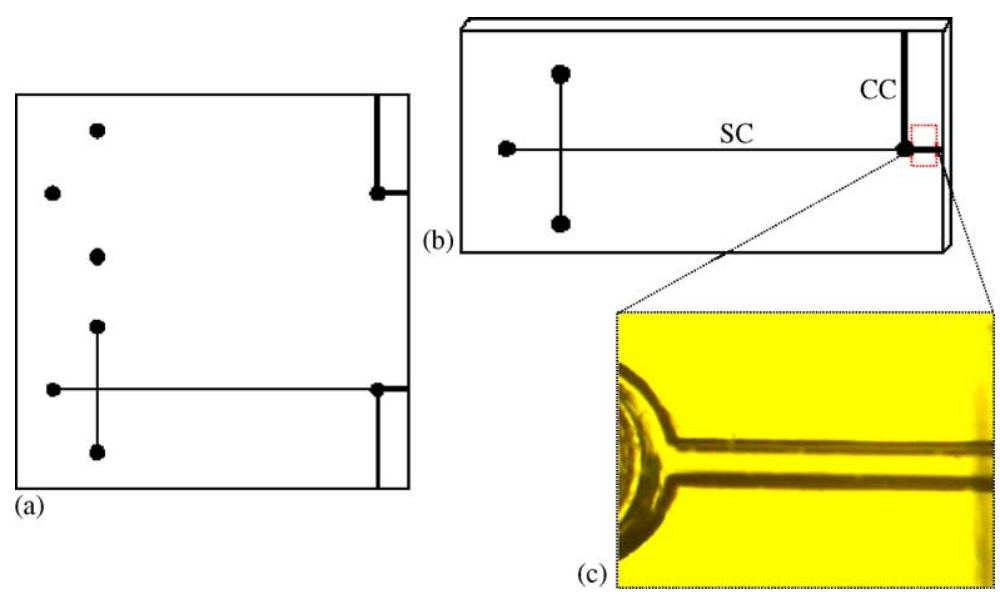

Fig. 1. Schematic diagrams of (a) mask of glass MCCE; (b) bonded glass MCCE; and (c) expanded view of MCCE guide tube for working electrode. SC, separation channel and CC, cathode channel. 
$\mathrm{NH}_{4} \mathrm{~F}-\mathrm{HF}$ etchant for $2.5 \mathrm{~h}$, then they were carefully covered by transparent adhensive film, which was resist to acids. The operation was finished with the aid of microscope, and other channels and reservoirs were etched $4 \mathrm{~h}$ more in $0.4 \mathrm{M}$ $\mathrm{NH}_{4} \mathrm{~F}-\mathrm{HF}$ etchant. The residual photoresist and $\mathrm{Cr}$ layer was removed and the lower half of the glass slide with channels (Fig. 1a) was drilled at the location of reserviors. The glass was split into two halves and cleaned. Then two halves were dried and bonded in a muffle at $650^{\circ} \mathrm{C}$ for $7 \mathrm{~h}$ (Fig. 1b), therefore guide tube (Fig. 1c) and cathode channel formed. The latter was designed to integrate and fix the cathode to MCCE. A $2.0 \mathrm{~cm}$-long Pt wire was inserted into the cathode channel and fixed to the bonded MCCE with epoxy, four reservoirs were also glued to MCCE with epoxy. Carbon fiber microdisk electrode was aligned and located at the end of separation channel under microscope and the distance between them was about $25 \mu \mathrm{m}$.

\subsection{Electrochemical detection}

Electrochemical detection was carried out with three electrodes: $30 \mu \mathrm{m}$-carbon fiber microdisk working electrode, $\mathrm{Pt}$ counter electrode and $\mathrm{AgCl} / \mathrm{Ag}$ reference electrode (Fig. 2). The fabrication process of carbon fiber microdisk electrode was the same as reference [20] except that $50 \mu \mathrm{m}$ I.D. capillary was employed in this work. $\mathrm{AgCl} / \mathrm{Ag}$ reference electrode was made in laboratory by placing a spiral silver wire coated with $\mathrm{AgCl}$ in a $3 \mathrm{~mm}$ O.D. glass capillary. A $0.5 \mathrm{~cm}$-long Pt wire was enclosed in one end of the capillary and saturated $\mathrm{KCl}$ solution was filled in. The other end of the capillary was sealed and the counter electrode was fixed outside the capillary. The detection potential was set to $0.9 \mathrm{~V}$ versus $\mathrm{AgCl} / \mathrm{Ag}$, which was determined from hydrodynamic voltammograms of CA (not shown). The sample interval was set to $0.1 \mathrm{~s}$ when $i-t$ curve mode was chosen, and working electrode was preconditioned for $1 \mathrm{~s}$ under $-1.5 \mathrm{~V}$ (versus $\mathrm{AgCl} / \mathrm{Ag}$ ) before each run.

\subsection{Capillary electrophoresis procedures}

The channels were filled with $0.1 \mathrm{M} \mathrm{NaOH}$ over night and then flushed with pure water for $10 \mathrm{~min}$. The channels were flushed with electrophoretic buffer for 15 min before sample was injected. Sample injection was carried out using simple injection without holdback voltage. A voltage of $1 \mathrm{kV}$ was applied between reservoir 2 (Fig. 2) and 4 (with reservoir 4 grounded) for a short time in order to inject sample into separation channel, then the voltage was shifted to reservoir 1 and 4 to begin separation while the other two reservoirs were floating.

\section{Results and discussion}

\subsection{Fabrication of guide tube}

Fig. $1 \mathrm{~b}$ is a schematic diagram of the glass chip. A $5.2 \mathrm{~cm}$ separation channel was intersected with injection channel perpendicularly and the effective separation length was $4.5 \mathrm{~cm}$. A $38 \mu \mathrm{m}$-deep separation and injection channel was fabricated after corrosion for $2.5 \mathrm{~h}$ at room temperature. The resultant channels had trapezoid size, but their depth didn't satisfy the requirements of guide tube and cathode channel, so further etching was necessary to obtain the proper size for guide tube and cathode channel. This is a two-step etching process. In the second step, a more concentrated etchant $(0.4 \mathrm{M})$ was adopted as a compromise of the etching rate and etching accuracy. The operation was relatively simple and easy since it was only necessary to control the etching time and etchant concentration. Fig. 1c is the expanded view of guide tube, which was obtained through microscope with CCD camera. It can be seen that the guide tube has regular shape and smooth brim. The final depth of guide tube and cathode cannel was measured to be 186 and $203 \mu \mathrm{m}$, respectively. The calculated average etching rates were 15 and $25 \mu \mathrm{m} / \mathrm{h}$ for the first and second etching stage, respectively.

Guide tube for working electrode was important to alignment between the end of separation channel and working electrode, and therefore to the reproducibility of current response between runs. In this work, the etching process was controlled so that $0.5 \mathrm{~cm}$-long guide tube was narrowly wider (about $12 \mu \mathrm{m}$ ) than the outer diameter $(360 \mu \mathrm{m})$ of the fused capillary in which the working electrode is contained, so the alignment was relatively accurate. On the other side,

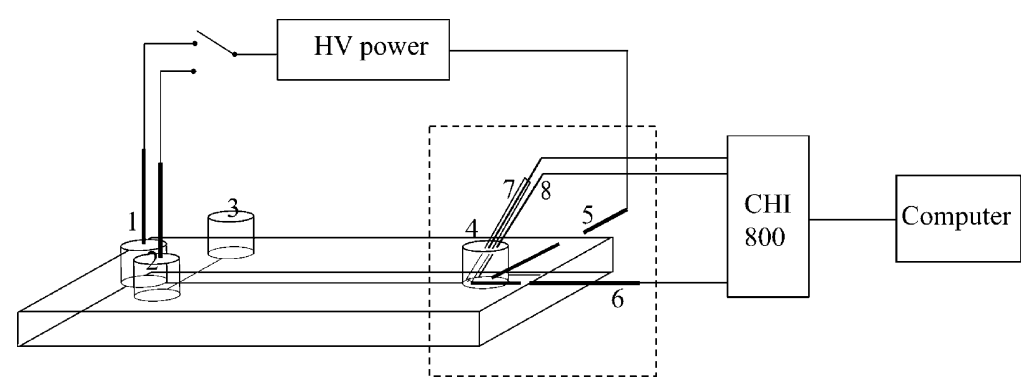

Fig. 2. Layout of MCCE system. (1), buffer reservoir; (2), sample reservoir; (3), sample waste; (4), detection reservoir; (5), cathode; (6), working electrode; (7), AgCl/Ag electrode; and (8), Pt counter electrode. Dotted line represents the Faraday cage. 


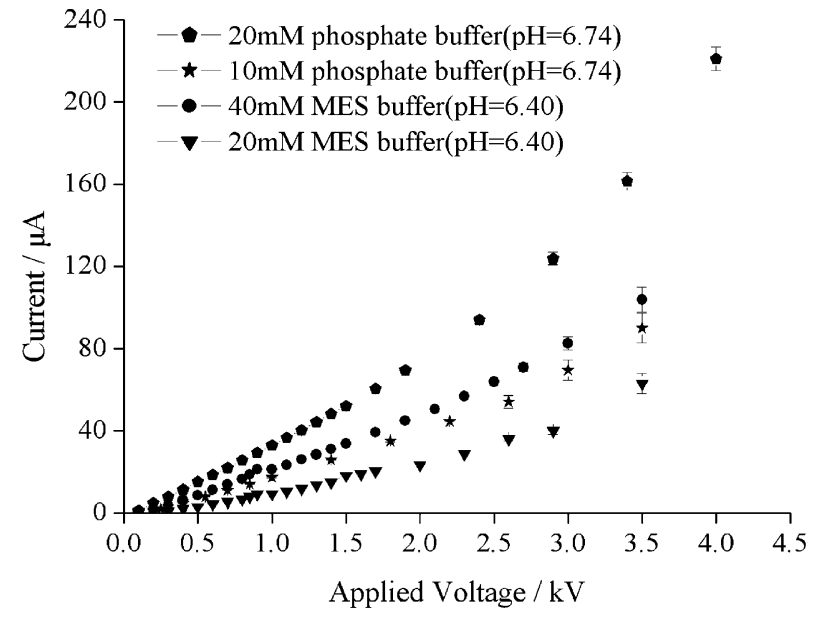

Fig. 3. $I-V$ curve of a glass MCCE. Conditions: $5.2 \mathrm{~cm}$ separation channel with average width $114 \mu \mathrm{m}$ and depth $38 \mu \mathrm{m}$.

guide tube was formed by two symmetric trapezoids because the substrate and cover plate of MCCE were etched under the same conditions, which also helped to place the working electrode to the center. Additionally, working electrode can be fixed or replaced quickly (about $30 \mathrm{~s}$ ) in the MCCE. The working electrode was fixed with epoxy in this work.

Compared with those alignment methods in PDMS [13-15], our alignment design using guide tube has advantages such as easy fabrication, working electrode replaceable. When the works by Wang et al. [17] and Zeng et al. [19] were concerned, the main differences lied in that the guide tube for working electrode was fabricated and integrated in the glass chip itself and the fabricate process was easier in this work. Besides, in the fabrication of carbon fiber microdisk working electrode, the process of pulling glass tube to suitable capillary which was reported in other papers $[19,21]$ was unnecessary.

\subsection{I-V curve}

The current-voltage plot was helpful to determine the maxium voltage where current was still steady. Fig. 3 is the $I-V$ curve for MES and phosphate buffer. When the concentration of the electrolyte rose, the current increased correspondingly. For $20 \mathrm{mM}$ phosphate buffer ( $\mathrm{pH}$ 6.74), when the voltage was above $1.2 \mathrm{kV}(40 \mu \mathrm{A})$, the electrodes began to emit bubbles and the current was unsteady when voltage was above $1.5 \mathrm{kV}(52 \mu \mathrm{A})$. In contrast, the current was unsteady when voltage was above $1.4 \mathrm{kV}(25.9 \mu \mathrm{A})$ for $10 \mathrm{mM}$ phosphate (pH 6.74). The same thing happened to $40 \mathrm{mM}$ MES when voltage exceeded $1.8 \mathrm{kV}$. These phenomena had been discussed before [2]. The correlation coefficiency for 20, $10 \mathrm{mM}$ phosphate and 40, $20 \mathrm{mM}$ MES was 0.9998 , $0.9982,0.9996$, and 0.9928 , respectively when voltage was not more than $1.5 \mathrm{kV}(300 \mathrm{~V} / \mathrm{cm})$, so a voltage lower than $1.5 \mathrm{kV}$ was applied in the following to ensure the steady

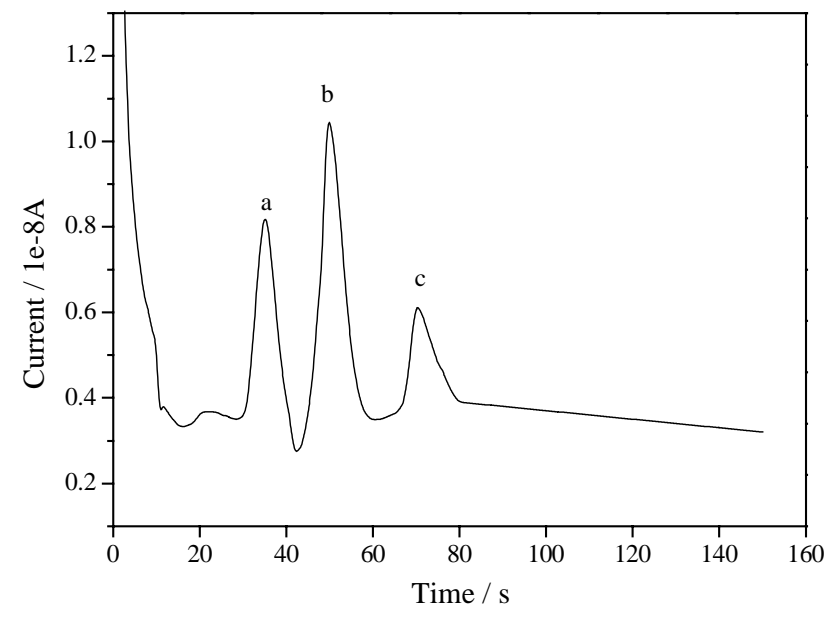

Fig. 4. Electrophorogram of a mixture of (a) $0.1 \mathrm{mM}$ DA and (b) $0.1 \mathrm{mM}$ $\mathrm{EP}$; and (c) $0.2 \mathrm{mM} \mathrm{CA}$. Conditions: $1 \mathrm{kV}$ separation voltage, $0.9 \mathrm{~V}$ detection potential (vs. $\mathrm{AgCl} / \mathrm{Ag}$ ), $8 \mathrm{~s}$ simple electrokinetic injection at $1 \mathrm{kV}$, $10 \mathrm{mM}$ phosphate buffer ( $\mathrm{pH} 7.00)$.

electrophoresis current and efficient dissipation of Joule heat.

\subsection{Separation DA, $C A$, and EP}

Neurotransmitters are vital to the metabolism of mankind, so it is very important to separation and determination different neurotransmitters. On the other hand, neurotransmitters have good redox activity therefore fit for studying the performance of the home-made MCCE with amperometric detector. Fig. 4 was the electrophorogram of two neurotransmitters: DA, EP, and CA in MCCE. Since DA and EP were positive ions, while CA was nearly neutral molecular when $\mathrm{pH}$ 7.0, DA and EP migrated fast than CA. The migration times of DA, EP, and CA were $35.1,49.9$, and $70.3 \mathrm{~s}$, respectively and the theoretical plate numbers $(N)$ were 5610 , 9776 , and 18727 , respectively. The peak currents for three substance were $5.08,7.45$, and $2.40 \mathrm{nA}$, which was higher than some references $[10,19]$ and implied good current response. It can be found from Fig. 4 that three substance obtained baseline resolution within $80 \mathrm{~s}$ and Rs was 1.36 between DA and EP, and 1.81 between EP and CA.

\subsection{Injection time}

Injection time was a very important parameter in the separation. In this work, the influence of injection time on DA and CA was explored and the results are illustrated in Fig. 5. It was evident that with the prolonging of injection time, the theoretical plate number for CA increased from 18010 to 19830 then decreased. Theoretical plate number reached its climax when sample was injected for $8 \mathrm{~s}$. Theoretical plate number for DA had the similar variation tendency and also reached the optimal value when injection time was set to $8 \mathrm{~s}$. In the following experiments, an injection time of $8 \mathrm{~s}$ was adopted. 


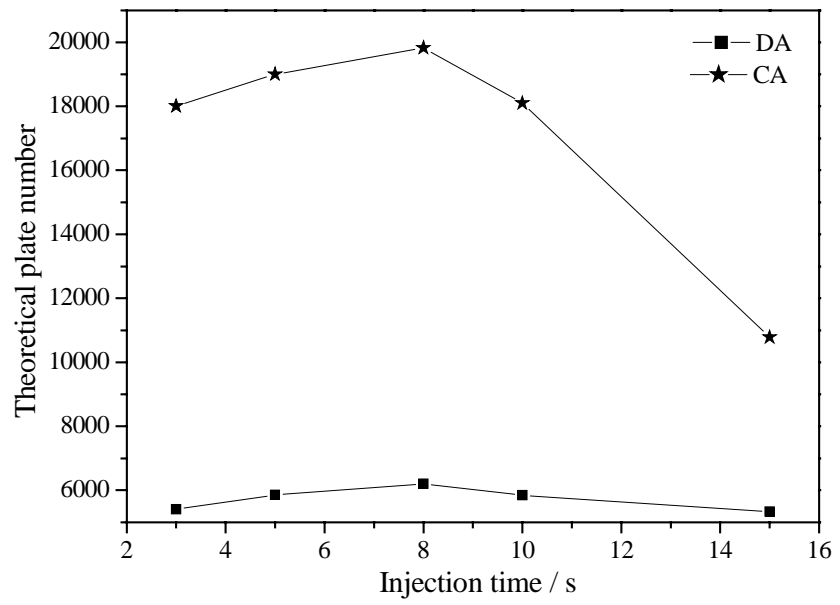

Fig. 5. Effect of injection time on separation of DA and CA. Conditions are the same as in Fig. 4.

\subsection{Buffer choice}

Phosphate, $100 \mathrm{mM}$ Tris and $50 \mathrm{mM}$ citric acid in $N, N$-dimethylformamide (DMF) were examined. Organic solvents had lower current and therefore produced little Joule heat. However, many organic solvents would temper the transfer of electron, therefore, peak current decreased according to our experiments (data not shown). That is, less sensitive current responses were obtained in DMF solvent for DA and CA. So, phosphate buffer was used in the following experiments to obtain good current response.

The concentration and $\mathrm{pH}$ of buffer had impact on the separation performance. Separation was carried out with $\mathrm{pH}$ being 5.65, 6.28, 6.53, 6.94, and 7.26, respectively. Three parallel experiments were carried out at each $\mathrm{pH}$ value. Fig. 6 displays the influence of $\mathrm{pH}$ on the resolution ( $\mathrm{Rs}$ ) between DA and CA as well as on the migration times of DA and CA. As expected, the migration time of DA decreased from

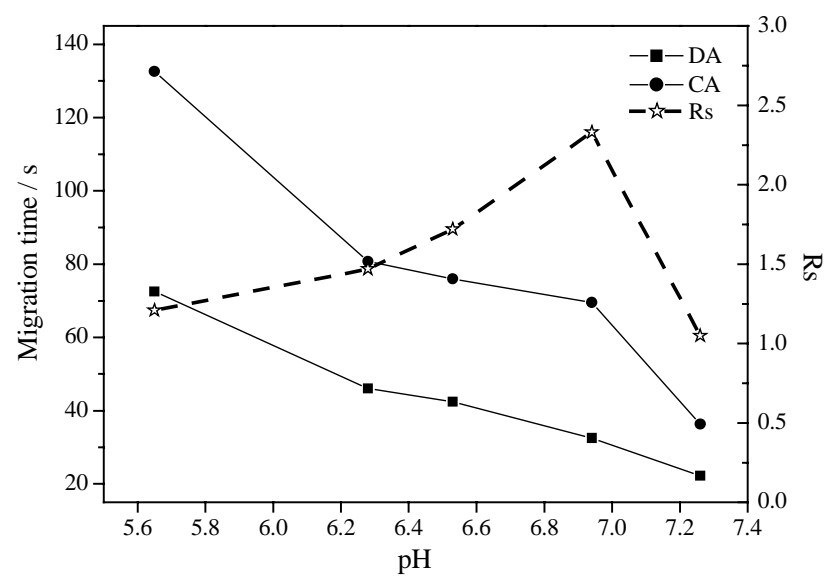

Fig. 6. Effect of $\mathrm{pH}$ on separation of $0.1 \mathrm{mM}$ DA and $0.2 \mathrm{mM}$ CA. Conditions are the same as in Fig. 4 except that injection was finished at $1 \mathrm{kV}$ for $10 \mathrm{~s}$.

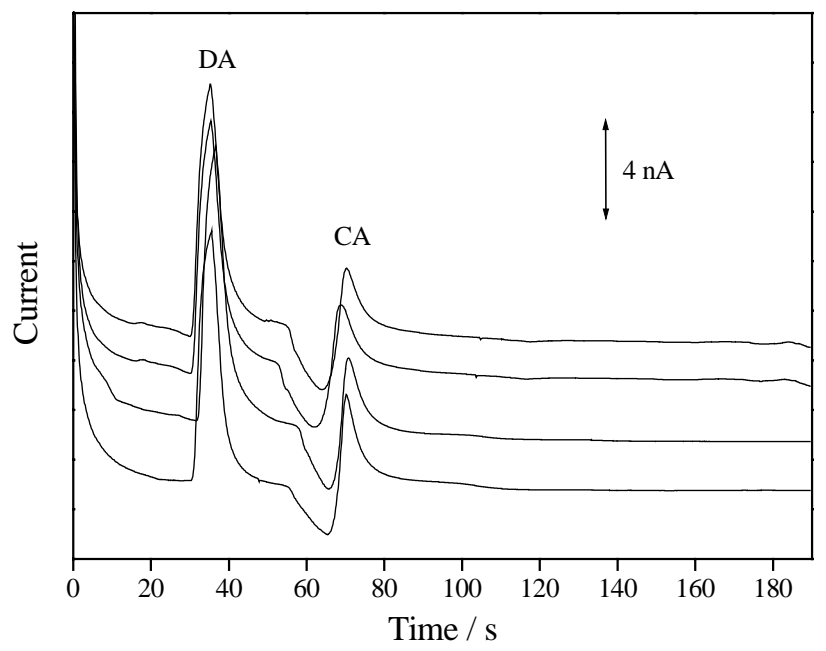

Fig. 7. Four continuous runs of $0.2 \mathrm{mM}$ (a) DA and (b) CA. Conditions are the same as in Fig. 6.

71.7 to $22.3 \mathrm{~s}$ as $\mathrm{pH}$ rose between 5.65 and 7.26 while from 132.6 to $36.1 \mathrm{~s}$ for CA. Rs increased from 1.21 at $\mathrm{pH} 6.53$ then reached its maximum 2.33, where $\mathrm{pH}$ is 6.94 , and then decreased again. It can be explained that Rs depended on two parameters migration time difference $\left(\Delta t_{\mathrm{BA}}\right)$ and peak width of adjacent analytes $\left(w_{\mathrm{B}}+w_{\mathrm{A}}\right)$. It was well known that the electro-osmotic flow (EOF) became faster with the increase of $\mathrm{pH}$ in fused silica capillary as well as glass channel in MCCE. The migration times of DA and CA, and peak width summation decreased with the increase of $\mathrm{pH}$, but these two parameters had reverse effect on the separation. When $\mathrm{pH}$ value was not more than 6.94 , the decrease of $\Delta t_{\mathrm{BA}}$ exceeded the decrease of peak width summation $\left(w_{\mathrm{B}}+w_{\mathrm{A}}\right)$, so Rs increased and reached its climax at $\mathrm{pH}$ value of 6.94. However, the range trend of $w_{\mathrm{B}}+w_{\mathrm{A}}$ and $\Delta t_{\mathrm{BA}}$ reversed when $\mathrm{pH}$ value was between 6.94 and 7.26. This resulted in the decrease of Rs. The theoretical plate numbers also arrived its climax at $\mathrm{pH}$ value of 6.94 , and they were calculated to be 6800 and 21040 for DA and CA, respectively.

\subsection{Reproducibility}

Reproducibility of the separation of DA and CA was studied in order to examine the performance of guide tube and glass MCCE. Fig. 7 shows four parallel runs of $0.2 \mathrm{mM} \mathrm{DA}$ and $0.2 \mathrm{mM} \mathrm{CA}$. At $\mathrm{pH} 6.94$, the average migration times of DA and CA were 35.7 and $70.1 \mathrm{~s}$, respectively. Relative standard deviations (RSDs) of migration times for DA and CA were 1.0 and $1.2 \%$, respectively. RSDs of peak currents $\left(i_{\mathrm{RSD}}\right)$ were 5.4 and $6.0 \%$ for DA and CA respectively, which were better than reference [23] and some what worse than $[19,22]$. Although migration times of DA and CA were fast $(<80 \mathrm{~s})$, RSDs of migration times $\left(t_{\mathrm{RSD}}\right)$ of DA and CA were better compared with reference [22] and slightly better 

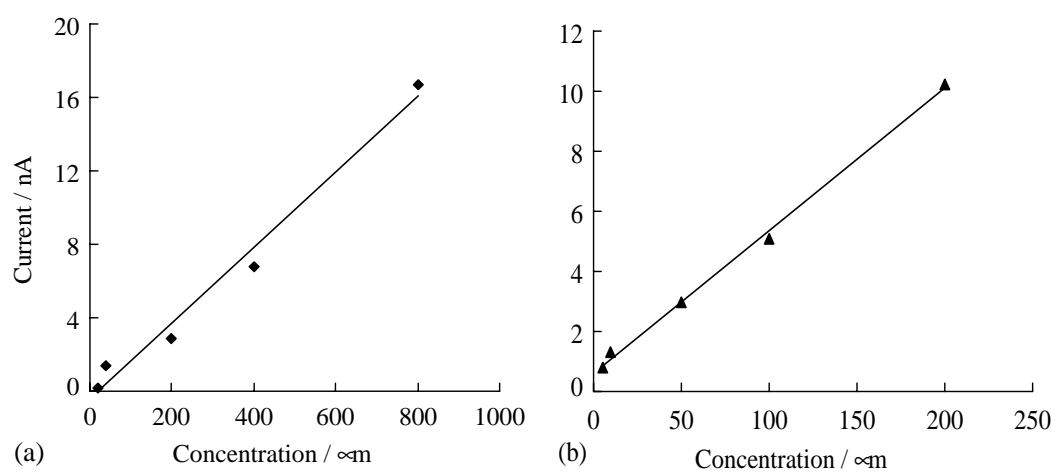

Fig. 8. Calibration curves for (a) CA and (b) DA. Conditions are the same as in Fig. 6 except that pH is 6.94 .

than reference [24]. Furthermore, electrophoresis operation was carried out manually in this work, so the reproducibility seemed good.

\subsection{Linear range and limits of detection}

The MCCE amperometric detector displayed well-defined concentration dependence. Fig. 8a and b shows the dynamic ranges for DA and CA. Five different concentrations were investigated. The response of DA was linear from 5 to $200 \mu \mathrm{m}$ with the correlation coefficiency $(r)$ to be 0.9987 , while CA was linear from 20 to $800 \mu \mathrm{m}(r=0.9912)$. The sensitivities of 47.3 and $20.6 \mathrm{pA} / \mu \mathrm{M}$ were obtained for $\mathrm{DA}$ and CA, respectively. By measuring $5 \mu \mathrm{m}$ DA alone with the same condition, the limit of detection (LOD) of DA was $0.51 \mu \mathrm{m}(\mathrm{S} / \mathrm{N}=3)$, which was more sensitive than some works $[22,23,25]$ while higher than reference $[16,19,26]$. The bigger electrode diameter thus the bigger background (about $20 \mathrm{pA}$ in this work versus $1.6 \mathrm{pA}$ in reference [17]) may partly explain the higher LOD, incomplete decoupling $(0.1 \mathrm{~V}$ higher detection potential implied) of detection circuit may be another reason. By determining $20 \mu \mathrm{m} \mathrm{CA}$, the LOD of CA was $2.9 \mu \mathrm{m}$ when $\mathrm{S} / \mathrm{N}=3$. The LODs may be lower by decreasing background noise, adopting better injection mode and further optimizing separation conditions.

\section{Conclusions}

An amperometric detector with designed guide tube for working electrode integrated in a glass MCCE was reported. The fabrication process of MCCE was discussed and characteristics of the chip were tested. DA, CA and EP were completely resolved within $80 \mathrm{~s}$. Some separation conditions of DA and CA were studied. Linear range for DA was 5-200 $\mu \mathrm{m}$, and $20-800 \mu \mathrm{m}$ for CA. LODs of DA and CA were 0.51 and $2.9 \mu \mathrm{m}$, respectively when $\mathrm{S} / \mathrm{N}=3$, LODs may be lowered further. Owing to advantages such as without using complicated three-dimension micropositioner, ease of aligning the working electrode with the end of separa- tion channel, and working electrode replaceable, the performance of MCCE was good on the whole.

\section{Acknowledgements}

This work was supported by National Science Fund for Distinguished Youth Scholars of China (20125514), National Natural Science Foundation of China (50273046, 20377046) and 863 Program (2001AA635030).

\section{References}

[1] A. Manz, D.J. Harrison, J.C. Fettinger, E. Verpoorte, H. Lüdi, H.M. Widmer, Transducers '91, Digest of Technical Papers, IEEE 91CH2817-5, New York, 1991, pp. 939.

[2] D.J. Harrison, A. Manz, Z. Fan, H. Ludi, H.M. Widmer, Anal. Chem. 64 (1992) 1926.

[3] W.R. Vandaveer IV, S.A. Pasas, R.S. Martin, S.M. Lunte, Electrophoresis 23 (2002) 3667.

[4] A.M. Leach, A.R. Wheeler, R.N. Zare, Anal. Chem. 75 (2003) 967.

[5] F. Dang, L. Zhang, H. Hagiwara, Y. Mishina, Y. Baba, Electrophoresis 24 (2003) 714.

[6] B. Zhang, F. Foret, B.L. Karger, Anal. Chem. 73 (2001) 2675.

[7] R.G. Su, F. Qu, J.M. Lin, Acta Chim. Sinica 61 (2003) 885.

[8] P.A. Greenwood, C. Merrin, T. McCreedy, G.M. Greenway, Talanta 56 (2002) 539.

[9] J. Wang, Talanta 56 (2002) 223.

[10] A.T. Woolley, L.Q. Lao, A.N. Glazer, R.A. Mathies, Anal. Chem. 70 (1998) 684

[11] R.S. Martin, A.J. Gawron, S.M. Lunte, Anal. Chem. 72 (2000) 3196.

[12] A.J. Gawron, R.S. Martin, S.M. Lunte, Electrophoresis 22 (2001) 242.

[13] R. Kikura-Hanajiri, R.S. Martin, S.M. Lunte, Anal. Chem. 74 (2002) 6370.

[14] C.S. García, C.S. Henry, Anal. Chem. 75 (2003) 4778.

[15] J. Wang, M.P. Chatrathi, A. Mulchandani, W. Chen, Anal. Chem. 73 (2001) 1804.

[16] J. Wang, B. Tian, E. Sahlin, Anal. Chem. 71 (1999) 5323.

[17] J. Wang, A. Escarpa, M.P. Chatrathi, J. Feldman, J. Chromatogr. A 952 (2002) 249.

[18] J. Wang, A. Ibáñez, M.P. Chatrathi, Electrophoresis 23 (2002) 3744.

[19] Y. Zeng, H. Chen, D.W. Pang, Z.L. Wang, J.K. Chen, Anal. Chem. 74 (2002) 2441. 
[20] X.H. Sun, X.R. Yang, E.K. Wang, J. Chromatogr. A 991 (2003) 109.

[21] U. Backofen, F.M. Matysik, C.E. Lunte, Anal. Chem. 74 (2002) 4054.

[22] J. Yan, Y. Du, J. Liu, W. Cao, X. Sun, W. Zhou, X. Yang, E. Wang, Anal. Chem. 75 (2003) 5406.
[23] J. Wang, B.M. Tian, E. Sahlin, Anal. Chem. 71 (1999) 3901.

[24] N.E. Hebert, W.G. Kuhr, S.A. Brazill, Anal. Chem. 75 (2003) 2969.

[25] J.C. Fanguy, C.S. Henry, Electrophoresis 23 (2002) 767.

[26] D.C. Chen, F.L. Hsu, D.Z. Zhan, C.H. Chen, Anal. Chem. 73 (2001) 758. 